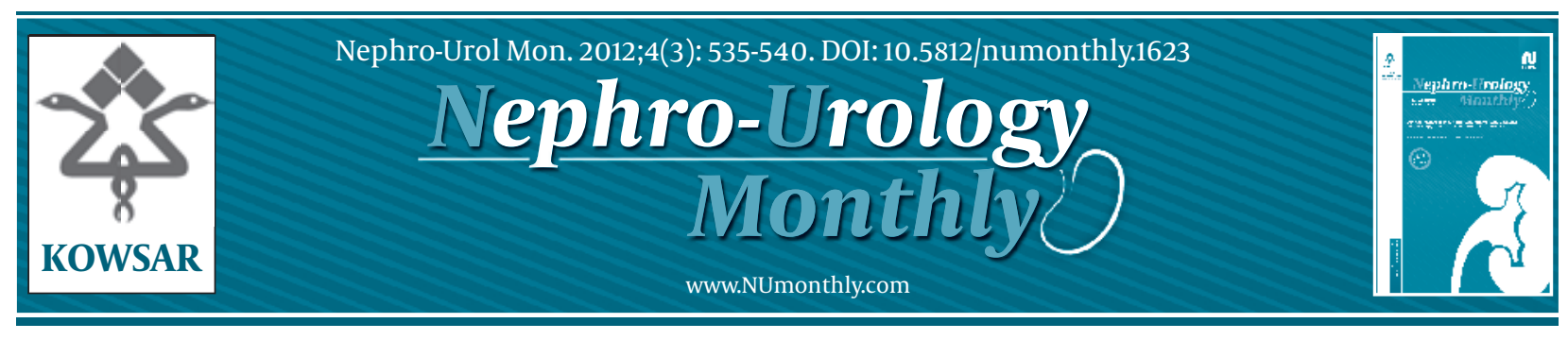

\title{
Outcome of Loupe-Assisted Sub-inguinal Varicocelectomy in Infertile Men
}

\author{
Selim S. Abdelrahman ${ }^{1}$, Bayoumy I. Eassa ${ }^{2^{*}}$ \\ ${ }^{1}$ Departments of Surgery, Al-Azhar University, Cairo, Egypt \\ 2 Department of Dermatology, Venereology and Andrology, Al-Azhar University, Cairo, Egypt
}

\begin{tabular}{l}
\hline A R T I C L E I N F O \\
\hline Article type: \\
Original Article \\
\hline Article history: \\
Received: 14 Jun 2011 \\
Revised: : 07 Sep 2011 \\
Accepted: 18 Sep 2011 \\
\hline
\end{tabular}

A B S T R A C T

Keywords:

Varicocele

Infertility

Semen

Background: Sub-inguinal varicocelectomy is widely used among surgeons.

Objectives: The aim of this study was to evaluate the outcome of varicocelectomy using a modified microsurgical method, specifically a loupe-assisted method, and its effects on sperm parameters in infertile men.

Patients and Methods: This study was performed in 40 patients who presented with varicocele. All patients had at least a 1-year history of infertility with abnormal semen parameters and varicocele proven by physical examination and confirmed with color Doppler ultrasound. Routine preoperative investigations were performed. Semen analysis and hormonal profiling were also performed and repeated postoperatively for followup. Half of the patients ( 20 patients) were treated by a sub-inguinal approach assisted by loupe magnification (Group A) and the other half was treated by the same approach but without magnification (Group B). To facilitate the procedure, an $\times 3.0$ loupe was used during the spermatic cord dissection at the level of the external inguinal ring. During dissection, the dilated veins, including the vassal veins and external spermatic veins, were ligated and divided.

Results: In total, 40 patients were followed for more than 6 months. The age of the patients varied from 25 to 38 years (mean 32.5). No intra-operative complications occurred in both groups. Regarding post-operative complications, Group A contained only one patient (5\%) who developed scrotal hematoma and two (10\%) who developed wound infection, whereas in Group B, the complication rate was higher: two patients $(10 \%)$ developed scrotal hematoma, two patients (10\%) developed wound infection, three patients (15\%) developed hydrocele, two patients (10\%) developed recurrence, and two patients $(10 \%)$ developed scrotal edema. Regarding the seminal parameters, much improvement was observed in the sperm count and sperm motility, and a decrease in abnormal forms was observed after surgery with significant differences in Group A. In Group B, similar effects were observed, but without significant differences.

Conclusions: Loupe-assisted sub- inguinal varicocelectomy is a safe, simple, and effective method for the treatment of sub-fertile men, especially in medical facilities without microscopic equipment, and permits significant improvement in sperm parameters.

Copyright $\odot 2012$ Kowsar Corp. All rights reserved.

- Implication for health policy/practice/research/medical education:

From this article we emphasis that, Loupe-assisted sub-inguinal varicocelectomy is a safe, simple, and effective method for the treatment of sub-fertile men and provides a significant improvement in sperm parameters, so it should be used, especially in developing country where the microsurgery equipment not available every where.

- Please cite this paper as:

Abdelrahman SS, Eassa BI. Outcome of Loupe Assisted Sub-inguinal Varicocelectomy in Infertile Men. Nephro-Urol Mon. 2012;4(3): 535-40. DOI: 10.5812/numonthly.1623

${ }^{*}$ Corresponding author: Bayoumy Ibrahim Eassa, Department of Dermatology, Venereology and Andrology, Faculty of Medicine, Al-Hussein University Hospital, Al-Azhar University, Cairo, Egypt. Tel: +20-24556558, Fax: +20-225104146, Email: bayeassa@yahoo.com/sahar10469@yahoo.com

DOI:10.5812/numonthly.1623

Copyright @2012 Kowsar Corp. All rights reserved.

\section{Background}

Varicocele is characterized by the elongation, dilatation and abnormal kinking of the spermatic veins of the pampiniform plexus of the testis (1). Celsius, the Greek 
physician, mentioned this disease for the first time as testicular atrophy in the first century $\mathrm{AD}(2)$. The incidence of varicocele in the male population is $15-20 \%$ (3). The fraction of clinically evidenced varicocele in young adult subjects varies from $9 \%$ to $23 \%$, as reported by the most recent studies. Furthermore, varicocele is observed in over $40 \%$ of infertile persons $(4,5)$. Approximately $12-25 \%$ of men being examined for infertility have moderate to large varicocele, and approximately $15 \%$ have small or sub-clinical varicocele $(6,7)$.

Various studies have demonstrated inconsistent and contradictory results that have led physicians to dissociate varicocele and male infertility. Male fertility may be preserved with only a single healthy testis, whereas infertility represents bilateral testicular dysfunction, so it is difficult to explain bilateral testicular dysfunction with left sided varicocele (8). There are two primary reasons for the controversy regarding the role of varicocelectomy in the management of infertility. First, there is no well-defined etiologic mechanism of varicocele affecting spermatogenesis. It has been postulated that the harmful effect of varicocele in spermatogenesis caused by an increase in the intrascrotal temperature but the exact pathogenic mechanisms that result from raised temperature have not been clearly defined. The second problem is that no well-designed study has proven the beneficial role of surgery $(9,10)$.

The role of varicocele in the impairment of testicular function and infertility was investigated in men presenting to infertility clinics and documented by the World Health Organization (WHO). Scrotal pain, testicular atrophy, and infertility without other apparent causes are the common indications for the correction of varicocele, whereas surgery in adolescent varicocele, sub-clinical varicocele and azoospermia remains controversial (11). In varicocele, unrelieved venous stasis interferes with the normal testicular temperature, which is usually maintained at $2-3^{\circ} \mathrm{C}$ lower than the core body temperature (12). Continuous exposure to high temperature causes sub-fertility by decreasing testicular volume, spermatogenesis, and semen quality as well as increasing the amount of immature sperm in the ejaculate (13).When clinical palpable varicocele coexists with impaired semen quality, surgical repair may potentially restore spermatogenesis and fertility (14-16).

The internal spermatic veins are responsible for the testicular venous drainage, but the failure of varicocele repair may be caused by collateral channels such as external spermatic veins or vassal veins $(17,18)$ Varicocelectomy requires the meticulous inspection of the spermatic cord and it is of prime importance to identify and avoid injury to the arterial blood supply and lymphatic channels to the testicles (19). Contrary to classical descriptions of testicular arterial anatomy that depict a single testicular artery branching at the level of the scrotum, the surgeon must be well versed with the knowledge of the testicular arterial anatomy during surgery of the spermatic cord and scrotal structures to ensure that testicular function and male fertility potential are preserved (20).

Many investigators using both clinical and histological analyses have documented the presence of multiple arterial branches within the inguinal spermatic cord as far proximally as the internal ring $(21,22)$. Jarow et al., 1992, examined the spermatic cords using loupe magnification for 12 men who underwent inguinal varicocelectomy and reported 1-3 (mean of 2) testicular arteries within the inguinal spermatic cord (23). Hopps et al., 2003; identified two arteries in $42 \%$ of all dissections and three arteries in $33 \%$ in the spermatic cords during microsurgical varicocelectomy at the sub-inguinal level (24). Several surgical techniques have been described, including the Palomo operation (ligation of internal spermatic veins) in the retroperitoneal space (25), modified Palomo operation (ligation of the vascular pedicle above the vas deferens) by opening the external oblique aponeurosis (26), and the sub-inguinal approach of Ivanissevich (ligation of the vascular pedicle at the superficial inguinal ring) without opening the external oblique aponeurosis (27). Loupes or an operating microscope is used for optical magnification by most experts who perform inguinal or sub-inguinal surgical repair, and this technique maximizes preservation of arterial and lymphatic vessels while reducing the risk of persistence or recurrence of varicocele (28).

\section{Objectives}

The aim of this study was to evaluate the outcome of varicocelectomy using a modified microsurgical method, specifically a loupe-assisted method, and its effects on sperm parameters in infertile men.

\section{Patients and Methods}

\subsection{Protocol}

During a 3-year period, 40 patients with varicocele and primary infertility were included in this prospective study. Half of the patients ( 20 patients) were treated by a sub-inguinal approach assisted with loupe magnification (Group A) and the other half (20 patients) by the same approach but without magnification (Group B). Written consent was obtained from all patients after an explanation was provided regarding the nature of operation. Routine preoperative investigations were performed and included the complete blood count (CBC), blood glucose, liver function test (LFT), renal function test (RF), coagulation profile, blood grouping and hepatitis $\mathrm{B}$ and $\mathrm{C}$ antibodies. Exclusion criteria included previous inguinal or scrotal surgery (varicocelectomy, cryptorchidism or hernia repair), secondary infertility, azoospermia and female factors or any finding contraindicated for surgery. All of the patients presented with infertility for least 1 year without history of any medical treatment that can affect sperm parameters for at least 3 months prior to this study. Varicocele was diagnosed clinically and further confirmed using color Doppler ultrasound. 
Physical examination, semen analysis and hormonal evaluation including FSH, $\mathrm{LH}$, total testosterone and prolactin hormones were performed for each patient. The physical examination (left or right, unilateral or bilateral varicocele) and the grade (Grade I to III) of varicocele were determined by inspection and palpation with the patient in an upright position. The grades of varicocele were classified by using various methods including physical examination and confirmed by scrotal ultrasound and Doppler examination. The criteria were: Grade I (small), detected by palpation with difficulty but increased by Valsalva's maneuver; Grade II (moderate), detected easily by palpation without Valsalva's maneuver; Grade III (large), detected visually at a distance.

At least three semen samples were collected by masturbation after 3 days of abstinence and used for preoperative semen analysis according to World Health Organization guideline 1999 for each patient. All patients were examined at 3 and 6 months postoperatively, which included semen analyses for the assessment of sperm concentration, motility and abnormal morphology of spermatozoa, hormonal profile, scrotal ultrasound, and color Doppler. The recurrence of varicocele, hydrocele and or any other complications after surgical correction of varicocele was regularly assessed.

\subsection{Surgical Technique}

In group A, the patient was placed in the supine position under spinal anesthesia. The incision was made transversely with a length of approximately 2 to $2.5 \mathrm{~cm}$ at the level of external inguinal ring, just outside the pubic tubercle. The external ring was not opened; therefore, the inguinal canal was kept intact. By retracting the edges of the wound, the spermatic cord could be identified by the appearance of the blue color of the spermatic veins. After loosening of the spermatic cord by moving it medially and laterally, the cord could be looped and then easily externalized on a vascular tape without tension. The tissues external to the sper- matic cord were examined first for any engorged veins; if present, they were ligated accordingly. The external and intermediate spermatic fascia were opened to expose the internal spermatic veins and fat. After the internal spermatic fascia of the spermatic cord was opened, the dissection was continued with the aid of a 3.0 loupe. Lymphatics were characterized by their crystal clear intravascular contents. The arteries were identified by their clearly visible pulsations. The engorged internal spermatic veins were identified and dissected carefully with mosquito clamps. Manipulating the mosquito clamps under the target vessel by a gentle up-and-down movement helped to differentiate a vein from an artery or a lymphatic vessel. While the vessel was isolated, a loop of 3-0 Vicryl was passed beneath, and then the loop end was divided to make double ties. The vessel was ligated at both ends and severed with sharp scissors. The compartment of the vas deferens was protected and left untouched except when abnormally engorged veins were evident. After the procedures performed inside the spermatic cord were completed, the wound was closed subcutically with 4-0 Vicryl sutures.

The technique mentioned above was also performed for the Group B patients but without the aid of the magnifying loupe. In general, the testicle was not delivered from the wound; therefore, the gubernacular veins were not touched. The patients were discharged in the next morning. The semen parameter data are presented as the mean standard deviation (SD). $P<0.05$ was considered significant.

\section{Results}

In total, 40 patients were included in this study. The age of the patients varied from 25 to 38 years (mean 32.5). Re-

\begin{tabular}{lll}
\hline Table 1. Presenting Symptom & & \\
\hline Symptoms & Number & $\%$ \\
\hline Subfertility & 40 & 100 \\
Pain & 2 & 5 \\
\hline
\end{tabular}

\begin{tabular}{|c|c|c|c|c|c|c|c|}
\hline Operation & $\begin{array}{l}\text { Sperm } \\
\text { Parameters, Mean } \pm \text { SD }\end{array}$ & $\begin{array}{l}\text { Before } \\
\text { Treatment, } \\
\text { Mean } \pm \text { SD }\end{array}$ & $\begin{array}{l}3 \text { Months After } \\
\text { Treatment, } \\
\text { Mean } \pm \text { SD }\end{array}$ & $P$ & Sig. & $\begin{array}{l}6 \text { Months After } \\
\text { Treatment, } \\
\text { Mean } \pm \text { SD }\end{array}$ & $P$ \\
\hline \multicolumn{8}{|c|}{ Group (A) Loupe-assisted varicocelectomy } \\
\hline & Sperm count, $\times 10^{6} / \mathrm{mL}$ & $15 \pm 5$ & $35 \pm 10$ & $<0.0001$ & $\mathrm{~S}^{\mathrm{a}}$ & $37 \pm 11$ & $<0.0001$ \\
\hline & Sperm motility \% & $24 \pm 8$ & $45 \pm 14$ & $<0.0001$ & $S$ & $48 \pm 15$ & $<0.0001$ \\
\hline & $\begin{array}{l}\text { Abnormal sperm } \\
\text { morphology \% }\end{array}$ & $54 \pm 17$ & $30 \pm 9$ & $<0.0001$ & $S$ & $29 \pm 8$ & $<0.0001$ \\
\hline \multicolumn{8}{|c|}{ Group (B) Varicocelectomy without loupe assistance } \\
\hline & Sperm count, $\times 10^{6} / \mathrm{mL}$ & $17 \pm 6$ & $20 \pm 6$ & 0.12 & $\mathrm{NS}^{\mathrm{a}}$ & $21 \pm 9$ & 0.11 \\
\hline & Sperm motility \% & $25 \pm 8$ & $30 \pm 10$ & 0.09 & NS & $32 \pm 15$ & 0.07 \\
\hline & $\begin{array}{l}\text { Abnormal sperm } \\
\text { morphology \% }\end{array}$ & $51 \pm 15$ & $45 \pm 14$ & 0.20 & NS & $43 \pm 13$ & 0.08 \\
\hline
\end{tabular}

a Abbreviations: NS, not significant; S, significant 


\begin{tabular}{lllllll}
\hline Table 3. Pre and Postoperative Hormonal Levels in Both Groups & & & & \\
\hline Hormones & $\begin{array}{l}\text { Preoperative, } \\
\text { Mean } \pm \text { SD }\end{array}$ & $\begin{array}{l}\text { 3 Months } \\
\text { Postoperative, } \\
\text { Mean } \pm \text { SD }\end{array}$ & P & Sig, & $\begin{array}{l}\text { 6 Months } \\
\text { Postoperative, } \\
\text { Mean } \pm \text { SD }\end{array}$ & P \\
\hline $\begin{array}{l}\text { Testosterone, } \\
\text { mmol/L }\end{array}$ & $10.2 \pm 3$ & $18.9 \pm 7$ & $<0.0001$ & $S^{\text {a }}$ & $19.4 \pm 8$ & $<0.0001$ \\
FSH, IU/L & $12 \pm 4$ & $11 \pm 3.5$ & 0.24 & NS & $12 \pm 3$ & 1 \\
LH, IU/L & $3.1 \pm 1$ & $3.5 \pm 1.3$ & 0.13 & NS & $3.2 \pm 1.5$ & 0.08 \\
Prolactin, mlU/L & $60 \pm 16$ & $61 \pm 13$ & 0.76 & NS & $61 \pm 14$ & 0.77 \\
\hline
\end{tabular}

${ }^{a}$ Abbreviations: NS, non significant; S, significant

\begin{tabular}{lll}
\hline Table 4. Post-Operative Complications & \\
\hline Complication & $\begin{array}{l}\text { Group A, No.(\%) } \\
(\mathbf{n = 2 0})\end{array}$ & $\begin{array}{l}\text { Group B, No.(\%) } \\
(\mathbf{n = 2 0})\end{array}$ \\
\hline Scrotal hematoma & $1(5)$ & $2(10)$ \\
Wound infection & $2(10)$ & $2(10)$ \\
Hydrocele & - & $3(15)$ \\
Recurrence & - & $2(10)$ \\
Scrotal edema & - & $2(10)$ \\
\hline
\end{tabular}

garding the varicocele grading, 20 patients (50\%) were grade III, 12 patients (30\%) were grade II and 8 patients (20\%) were grade I. In 38 patients (95\%), the varicocele was on the left side, whereas it was on the right side in two patients (5\%). All patients presented with subfertility, but two patients (5\%) also complained of intolerable pain, and five patients (12.5\%) with visible deformity in addition to infertility (Table 1).

When comparing pre-operative and post-operative semen parameters in Group A, there was a significant increase in the sperm concentration and in the percentage of motile spermatozoa, as well as significant reduction in spermatozoa with abnormal morphology, as early as the third month after varicocelectomy Table 2.The three parameters became normal during the following three months. In Group B, there was an increase in the sperm concentration among the motile spermatozoa as well as a reduction in the spermatozoa with abnormal morphology, but without significant differences. There was a significant postoperative increase in the level of testosterone in both groups, but the other hormones (FSH, LH and practin) remained unchanged, as shown in Table 3.

Regarding post-operative complications, in Group A only one patient (5\%) developed scrotal hematoma and two (10\%) developed wound infection, whereas in Group (B) the complication rate was higher, with two patients (10\%) developing scrotal hematoma, two (10\%) developing wound infection, three (15\%) developing hydrocele, two (10\%) developing recurrence, and two (10\%) developing scrotal edema as shown in Table 4.

\section{Discussion}

The association between clinical varicocele and impaired spermatogenesis is well described (29). Varicocele is the most frequently observed surgically correctable cause of male infertility (30). The exact pathophysiology of varicocele remains unknown, but it has been previously reported that the reflux of renal prostaglandins may underlie the testicular injury (31). Recent studies on the mechanism of varicocele-induced infertility note an increase in testicular temperature caused by the impairment of the countercurrent heat exchange mechanism (32). Subfertile men with varicoceles usually present with asthenospermia, teratospermia, oligospermia, or combinations of these features, and varicocelectomy is usually indicated, but it is not possible to predict who will ultimately benefit. Improvement in the quality of semen occurred in $51-74 \%$ of the patients and the pregnancy rate increased to $24-71 \%$ after varicocelectomy, whereas others have found no beneficial effect of varicocelectomy on pregnancy rates or semen quality (33).

Varicocele can be treated by a routine surgical intervention (varicocelectomy), microsurgery varicocelectomy, which is considered as the gold standard approach to varicocele repair (19), or by radiological embolization (34). Routine varicocelectomy is still the most popular treatment, even in the era of assisted reproductive techniques when treatment at the gamete level is feasible (35). Different outcomes, including increased pregnancy rate or improvement in one, two, or all the three seminal parameters have been used to evaluate the success rate of varicocelectomy (36). In a review of varicocele repair, Ficarra et al. (2006) they found a significant increase in the pregnancy rate of patients who underwent varicocele treatment (36.4\%) compared with patients who received no treatment (20\%) (15). In another study by Marmar et al. (2007), the pregnancy rate in patients who underwent surgical varicocelectomy was $33 \%$ as compared to $15.5 \%$ in the controlled patients who received no varicocelectomy (16).

Watanabe et al. (2005) stated that the sub-inguinal microscopic procedure is a minimally invasive varicocelectomy technique because of its postoperative mobility and is an effective treatment for infertile men with left clinical varicocele (37). Several studies indicate that larger varicoceles are associated with greater impairment of spermatogenesis (38), whereas others suggest that varicocele size does not correlate with the response to surgery (39). It is pro- 
posed that the varicocele must be treated when all of the following conditions are present: the couple's infertility is documented, the varicocele is palpable, there is no incurable infertility problem in the female, and at least one abnormality is present in the semen analysis (40).

During the past several decades, many different approaches or tools have been used for the treatment of varicocele with varying rates of success and complications. The best treatment modality for varicocele can be selected only after comparing the recurrence rate, improvement in semen parameters, and complication rates of these approaches (41). Recently, the sub-inguinal varicocelectomy, which was first described by Marmar (16), has become more popular because sub-inguinal varicocelectomy has a lower incidence of morbidity, complications, and residual lesions. However, this procedure reveals many more tedious small veins. Therefore, the need for more sophisticated microsurgical techniques steepens the learning curve (42). The high success rate of sperm recovery may be attributed to the preservation of the testicular artery and lymphatics (28). Although the necessity of preserving the testicular artery remains controversial, there are many reports of testicular atrophy following non-microsurgical conventional varicocelectomy or blind cord block only (43, 44). Possible adverse effects of hydrocele were reported by Szabo and Kessler (45). Postoperative hydrocele is highly correlated with varicocelectomy. In fact, the testicular artery and lymphatics can be accurately preserved by microsurgical varicocelectomy (46).

In our work, the complication rate of postoperative hydrocele was $0 \%$, which is superior to that of the conventional procedure. Reported incidences of postoperative hydrocele are between $7 \%$ and 30\% $(47,48)$. Abdel-Magidand Othman (2010) reported a postoperative hydrocele complication rate of $1.2 \%$ in the microsurgical subinguinal varicocelectomy group and 33.8\% in the non-magnified subinguinal varicocelectomy group (49). Another factor influencing the empirical outcome is the recurrence of postoperative varicocele. The usual general recurrence rate for varicocelectomy ranges from $15 \%$ to $25 \%(45,48)$. However, we had no recurrence in our study. The effect of varicoceles on sperm production alters spermatogenesis and often can result in the generalized impairment of sperm production, which is characterized by decreased sperm density and motility and an increase in immature spermatozoa ranging from oligozoospermia to complete azoospermia (50).

In the present study, there was a statistically significant increase in the sperm concentration and in the percentage of motile spermatozoa, as well as a significant reduction in the spermatozoa with abnormal morphology, as early as the third month after varicocelectomy. The three parameters became normal during the following 3 months, and this result is in agreement with the studies of Masanobu et al. (1996) (51), Cozzolino et al. (2001) (33), and Shamsa et al. (2010) (52). There was a significant increase in the postop- erative level of testosterone but the other hormones (FSH, $\mathrm{LH}$, and practin) showed no effect. This result is in agreement with studies by Cayan et al. (1999) (53); Podesta et al. (1994) (54) and Onozawa et al. (2002) (5). Varicocelectomy probably has positive effects on Leydig cell function. Defective testosterone synthesis has been reported to be associated with varicocele (55), probably through intratesticular hyperthermia, which inhibits 17a-hydroxyprogesterone aldolase, an enzyme responsible for the conversion of 17ahydroxyprogesterone to testosterone. Thus, Leydig cell function and serum free testosterone levels should be improved on removing the inhibition of 17a-hydroxyprogesterone aldolase by relieving intratesticular hyperthermia through varicocelectomy (56).

Varicocele is a common cause of infertility and is a curable disease in patients. Loupe-assisted sub-inguinal varicocelectomy provides a significant improvement in sperm parameters and is a safe, simple, and effective method for the treatment of sub-fertile men, especially in medical facilities without microscopic equipment.

\section{Acknowledgments}

There is no acknowledgment.

\section{Financial Disclosure}

There is no financial disclosure.

\section{Funding/Support}

There is no funding/support.

\section{References}

1. Granados Loarca EA, Alcahe Gallimidi VR, Escobar Monzon C, Echevarria Solis JC, de Leon Lopez H, Echevarria Reyes J. [The assessment of varicocele by ultrasound]. Actas Urol Esp. 1999;23(7):579-82.

2. Pryor JL, Howards SS. Varicocele. Urol Clin North Am. 1987;14(3):499-513.

3. Stanković J, Bošnjaković P. changes in sperm density caused by varicocele and their treatment by means of scleroembolization or high spermatic vein ligation. Medicine and Biology. 2006;13(1):15-8.

4. Segenreich E, Israilov S, Shmuele J, Niv E, Baniel J, Livne P. Evaluation of the relationship between semen parameters, pregnancy rate of wives of infertile men with varicocele, and gonadotropin-releasing hormone test before and after varicocelectomy. Urology. 1998;52(5):853-7.

5. Onozawa M, Endo F, Suetomi T, Takeshima H, Akaza H. Clinical study of varicocele: statistical analysis and the results of longterm follow-up. Int JUrol. 2002;9(8):455-61.

6. Baker HW, Burger HG, de Kretser DM, Hudson B, Rennie GC, Straffon WG. Testicular vein ligation and fertility in men with varicoceles. Br Med J (Clin Res Ed). 1985;291(6510):1678-80.

7. Organization WH. Towards More Objectivity in Diagnosis and Management of Male Infertility: Results of a World Health Organization Multicentre Study. Blackwell Scientific; 1987.

8. Gat Y, Zukerman Z, Chakraborty J, Gornish M. Varicocele, hypoxia and male infertility. Fluid Mechanics analysis of the impaired testicular venous drainage system. Hum Reprod. 2005;20(9):2614-9.

9. Zorgniotti AW, Macleod J. Studies in temperature, human semen quality, and varicocele. Fertil Steril. 1973;24(11):854-63. 
10. Yamaguchi M, Sakatoku J, Takihara H. The application of intrascrotal deep body temperature measurement for the noninvasive diagnosis of varicoceles. Fertil Steril.1989;52(2):295-301.

11. Williams DH, Karpman E, Lipshultz LI. Varicocele: surgical techniques in 2005. Can J Urol. 2006;13 (Suppl 1):13-7.

12. Fowler C. The testis and the scrotum. In: Charles V, Russell R, Norman S, editors. Bailey and Love's Short Practice of Surgery 25th Edition. 22th ed. New York: Arnold, Oxford University Press Inc;1999. p. 999-1010.

13. Amaku E. Principle and Practice of Surgery, Including Pathology in the Tropics. In: Badoe E, Archampong E, Jaja M, editors. Scrotum, Testis and Epididymis. 2nd ed ed: Ghana Publishing Corporation; 1994. p. 830-41.

14. Cayan S, Shavakhabov S, Kadioglu A. Treatment of palpable varicocele in infertile men: a meta-analysis to define the best technique. J Androl. 2009;30(1):33-40.

15. Ficarra V, Cerruto MA, Liguori G, Mazzoni G, Minucci S, Tracia A, et al. Treatment of varicocele in subfertile men: The Cochrane Review--a contrary opinion. Eur Urol. 2006;49(2):258-63.

16. Marmar JL, Agarwal A, Prabakaran S, Agarwal R, Short RA, Benoff $\mathrm{S}$, et al. Reassessing the value of varicocelectomy as a treatment for male subfertility with a new meta-analysis. Fertil Steril. 2007;88(3):639-48.

17. Sayfan J, Adam YG, Soffer Y. A new entity in varicocele subfertility: the "cremasteric reflux". Fertil Steril.1980;33(1):88-90.

18. Murray RR, Jr., Mitchell SE, Kadir S, Kaufman SL, Chang R, Kinnison ML, et al. Comparison of recurrent varicocele anatomy following surgery and percutaneous balloon occlusion. J Urol. 1986;135(2):286-9.

19. Grober ED, O'Brien J, Jarvi KA, Zini A. Preservation of testicular arteries during subinguinal microsurgical varicocelectomy: clinical considerations. J Androl. 2004;25(5):740-3.

20. Woodburne R. Essentials of Human Anatomy. 6th ed ed. New York, NY: Oxford University Press; 1978.

21. Beck EM, Schlegel PN, Goldstein M. Intraoperative varicocele anatomy: a macroscopic and microscopic study. J Urol. 1992;148(4):1190-4

22. Ergun S, Bruns T, Soyka A, Tauber R. Angioarchitecture of the human spermatic cord. Cell Tissue Res. 1997;288(2):391-8.

23. Jarow JP, Ogle A, Kaspar J, Hopkins M. Testicular artery ramification within the inguinal canal. J Urol.1992;147(5):1290-2.

24. Hopps CV, Lemer ML, Schlegel PN, Goldstein M. Intraoperative varicocele anatomy: a microscopic study of the inguinal versus subinguinal approach.J Urol. 2003;170(6 Pt 1):2366-70.

25. Palomo A. Radical cure of varicocele by a new technique; preliminary report. JUrol.1949;61(3):604-7.

26. Dubin L, Amelar RD. Varicocelectomy: twenty-five years of experience. Int J Fertil. 1988;33(4):226-8, 31-5.

27. Ivanissevich $O$. Left varicocele due to reflux; experience with 4,470 operative cases in forty-two years. J Int Coll Surg. 1960;34:742-55.

28. Goldstein M, Gilbert BR, Dicker AP, Dwosh J, Gnecco C. Microsurgical inguinal varicocelectomy with delivery of the testis: an artery and lymphatic sparing technique.J Urol.1992;148(6):1808-11.

29. Naughton CK, Nangia AK, Agarwal A. Pathophysiology of varicoceles in male infertility. Hum Reprod Update. 2001;7(5):473-81.

30. SAYPOL DC. Varicocele. Journal of Andrology. 1981;2(2):61.

31. Ito H, Fuse H, Minagawa H, Kawamura K, Murakami M, Shimazaki J. Internal spermatic vein prostaglandins in varicocele patients. Fertil Steril.1982;37(2):218-22.

32. Goldstein M, Eid JF. Elevation of intratesticular and scrotal skin surface temperature in men with varicocele. J Urol. 1989;142(3):743-5.

33. Cozzolino DJ, Lipshultz LI. Varicocele as a progressive lesion: positive effect of varicocele repair. Hum Reprod Update. 2001;7(1):55-8.

34. Goffette P, Hammer F, Mathurin P, Wese FX, Opsomer RJ, De Cooman S, et al. Recurrence of varicocele after spermatic vein embolization in young patients: radiological aspect. Acta Urol Belg. 1995;63(2):55-6.

35. Cornud F, Belin X, Amar E, Delafontaine D, Helenon O, Moreau
JF. Varicocele: strategies in diagnosis and treatment. Eur Radiol. 1999;9(3):536-45.

36. Schlesinger MH, Wilets IF, Nagler HM. Treatment outcome after varicocelectomy. A critical analysis. Urol Clin North Am. 1994;21(3):517-29.

37. Watanabe M, Nagai A, Kusumi N, Tsuboi H, Nasu Y, Kumon H. Minimal invasiveness and effectivity of subinguinal microscopic varicocelectomy: a comparative study with retroperitoneal high and laparoscopic approaches. Int JUrol. 2005;12(10):892-8.

38. Steckel J, Dicker AP, Goldstein M. Relationship between varicocele size and response to varicocelectomy.J Urol.1993;149(4):769-71.

39. Dhabuwala CB, Hamid S, Moghissi KS. Clinical versus subclinical varicocele: improvement in fertility after varicocelectomy. Fertil Steril.1992;57(4):854-7.

40. Wagner L, Tostain J. [Varicocele and male infertility: AFU 2006 guidelines]. Prog Urol. 2007;17(1):12-7.

41. Hsieh ML, Chang PL, Huang ST, Wang TM, Tsui KH. Loupe-assisted high inguinal varicocelectomy for sub-fertile men with varicoceles. Chang Gung Med J. 2003;26(7):479-84.

42. Tung MC, Huang WJ, Chen KK. Modified subinguinal varicocelectomy for painful varicocele and varicocele-associated infertility. J Chin Med Assoc. 2004;67(6):296-300.

43. Matthews GJ, Matthews ED, Goldstein M. Induction of spermatogenesis and achievement of pregnancy after microsurgical varicocelectomy in men with azoospermia and severe oligoasthenospermia. Fertil Steril.1998;70(1):71-5.

44. Penn I, Mackie G, Halgrimson CG, Starzl TE. Testicular complications following renal transplantation. Ann Surg. 1972;176(6):697-9.

45. Szabo R, Kessler R. Hydrocele following internal spermatic vein ligation: a retrospective study and review of the literature. J Urol. 1984;132(5):924-5

46. Huang SS, Wu CF, Chen CS. Subinguinal Microsurgical Varicocelectomy Under a Diagnosis of Color Flow Mapping: A Delicate and Effective Procedure for Varicocele. J UROL ROC. 2001;12(2):91-5.

47. Kaufman SL, Kadir S, Barth KH, Smyth JW, Walsh PC, White RI, Jr. Mechanisms of recurrent varicocele after balloon occlusion or surgical ligation of the internal spermatic vein. Radiology. 1983;147(2):435-40

48. Marmar JL, DeBenedictis TJ, Praiss D. The management of varicoceles by microdissection of the spermatic cord at the external inguinal ring. Fertil Steril. 1985;43(4):583-8.

49. Abdel-Maguid AF, Othman I. Microsurgical and nonmagnified subinguinal varicocelectomy for infertile men: a comparative study. Fertil Steril. 2010;94(7):2600-3.

50. Kim ED, Leibman BB, Grinblat DM, Lipshultz LI. Varicocele repair improves semen parameters in azoospermic men with spermatogenic failure. J Urol. 1999;162(3 Pt 1):737-40.

51. Takahara M, Ichikawa T, Shiseki Y, Nakamura T, Shimazaki J. Relationship between grade of varicocele and the response to varicocelectomy. Int J Urol. 1996;3(4):282-5.

52. Shamsa A, Nademi M, Aqaee M, Fard AN, Molaei M. Complications and the effect of varicocelectomy on semen analysis, fertility, early ejaculation and spontaneous abortion. Saudi J Kidney Dis Transpl. 2010;21(6):1100-5.

53. Cayan S, Kadioglu A, Orhan I, Kandirali E, Tefekli A, Tellaloglu S. The effect of microsurgical varicocelectomy on serum follicle stimulating hormone, testosterone and free testosterone levels in infertile men with varicocele. BJU Int. 1999;84(9):1046-9.

54. Podesta ML, Gottlieb S, Medel R, Jr., Ropelato G, Bergada C, Quesada EM. Hormonal parameters and testicular volume in children and adolescents with unilateral varicocele: preoperative and postoperative findings. J Urol. 1994;152(2 Pt 2):794-7; discussion 8.

55. Takeyama M, Honjoh M, Kodama M, Sakaguchi H, Koh E, Kondoh $\mathrm{N}$, et al. Testicular steroids in spermatic and peripheral veins after single injection of hCG in patients with varicocele. Arch Androl.1990;24(2):207-13.

56. Wright EJ, Young GP, Goldstein M. Reduction in testicular temperature after varicocelectomy in infertile men. Urology. 1997;50(2):257-9. 